\title{
Novel evidence for chronic exposure to endotoxin in human nonalcoholic steatohepatitis.
}

Citation for published version (APA):

Verdam, F. J., Rensen, S. S. M., Driessen, A. L. C., Greve, J. W. M., \& Buurman, W. A. (2011). Novel evidence for chronic exposure to endotoxin in human nonalcoholic steatohepatitis. Journal of Clinical Gastroenterology, 45(2), 149-152. https://doi.org/10.1097/MCG.0b013e3181e12c24

Document status and date:

Published: 01/01/2011

DOI:

10.1097/MCG.0b013e3181e12c24

Document Version:

Publisher's PDF, also known as Version of record

Document license:

Taverne

Please check the document version of this publication:

- A submitted manuscript is the version of the article upon submission and before peer-review. There can be important differences between the submitted version and the official published version of record.

People interested in the research are advised to contact the author for the final version of the publication, or visit the DOI to the publisher's website.

- The final author version and the galley proof are versions of the publication after peer review.

- The final published version features the final layout of the paper including the volume, issue and page numbers.

Link to publication

\footnotetext{
General rights rights.

- You may freely distribute the URL identifying the publication in the public portal. please follow below link for the End User Agreement:

www.umlib.nl/taverne-license

Take down policy

If you believe that this document breaches copyright please contact us at:

repository@maastrichtuniversity.nl

providing details and we will investigate your claim.
}

Copyright and moral rights for the publications made accessible in the public portal are retained by the authors and/or other copyright owners and it is a condition of accessing publications that users recognise and abide by the legal requirements associated with these

- Users may download and print one copy of any publication from the public portal for the purpose of private study or research.

- You may not further distribute the material or use it for any profit-making activity or commercial gain

If the publication is distributed under the terms of Article $25 \mathrm{fa}$ of the Dutch Copyright Act, indicated by the "Taverne" license above, 


\title{
Novel Evidence for Chronic Exposure to Endotoxin in Human Nonalcoholic Steatohepatitis
}

\author{
Froukje J. Verdam, MD, PhD, ${ }^{*}$ Sander S. Rensen, PhD, ${ }^{*}$ Ann Driessen, MD, PhD, $\dagger$ \\ Jan Willem Greve, MD, PhD,* and Willem A. Buurman, PhD*
}

\begin{abstract}
Background: Endotoxin is hypothesized to play an important role in the activation of inflammatory pathways associated with nonalcoholic steatohepatitis (NASH). However, demonstration of hepatic endotoxin exposure is challenging due to the inaccessibility of the portal circulation. Furthermore, reliable measurement of the relatively low endotoxin levels in plasma of patients with liver disease and subsequent interpretation remain difficult.
\end{abstract}

Goals: In this study, we used the EndoCab assay that measures endogenous antibodies to the core region of endotoxin to estimate hepatic endotoxin exposure over time.

Study: IgG levels against endotoxin were measured in peripheral plasma obtained from 21 severely obese patients with NASH and 9 severely obese patients with healthy livers.

Results: Plasma IgG levels against endotoxin were significantly elevated in patients with NASH compared with patients with healthy livers $(48 \pm 63 \mathrm{GMU} / \mathrm{mL}$ vs. $10 \pm 13 \mathrm{GMU} / \mathrm{mL})$. Moreover, these IgG levels progressively increased with NASH grade (grade $129 \pm 37$; grade $258 \pm 51$; grade $384 \pm 132 \mathrm{GMU} / \mathrm{mL}$, $P<0.05)$. There was no relation between plasma IgG levels and NASH stage.

Conclusions: Plasma IgG levels against endotoxin were found to be increased in biopsy-proven human NASH and increased with aggravated inflammation in NASH, suggesting a relationship between chronic endotoxin exposure and the severity of human NASH.

Key Words: antibodies to endotoxin, EndoCab, nonalcoholic fatty liver disease, leaky gut

Abbreviations: GMU indicates EndoCab standard median-units IgG; LAL, Limulus Amoebocyte Lysate; NASH, Non-alcoholic steatohepatitis.

(J Clin Gastroenterol 2011;45:149-152)

$\mathrm{N}$ onalcoholic steatohepatitis (NASH) is a liver disorder with an increasing incidence and a prevalence of $5.7 \%$ in the United States. ${ }^{1}$ Several lines of evidence support an important role for chronic exposure of the liver to bacterial

Received for publication January 13, 2010; accepted March 31, 2010. From the Departments of *General Surgery, Faculty of Health, Medicine and Life Sciences, NUTRIM School for Nutrition, Toxicology and Metabolism; and $†$ Pathology, Maastricht University Medical Centre, Maastricht, The Netherlands.

Disclosure: The authors have nothing to disclose. This research was supported by the Senter Novem Innovation Oriented Research Program on Genomics, grant IGE05012 and a Transnational University Limburg (TUL) grant (SR).

Reprints: Sander S. Rensen, PhD, Department of General Surgery, Maastricht University Medical Center, PO Box 616, 6200 MD Maastricht, The Netherlands (e-mail: s.rensen@ah.unimaas.nl).

Copyright (C) 2011 by Lippincott Williams \& Wilkins endotoxin in the pathogenesis of NASH in humans. First, small intestinal bacterial overgrowth has been shown to be associated with NASH. ${ }^{2-4}$ In addition, patients with NASH display an impaired intestinal barrier function. ${ }^{2,5}$ Together, this may lead to the reported increased plasma endotoxin levels in NASH. ${ }^{5,6}$

However, there are important concerns with respect to the analysis of endotoxin in the context of NASH. First, endotoxin levels in peripheral blood may not necessarily reflect hepatic endotoxin exposure, as the endotoxin is rapidly cleared from the portal circulation by the liver. ${ }^{7}$ In line with this observation, the reported increase in endotoxin levels in peripheral plasma of patients with NASH is relatively minor. ${ }^{5}$ Second, the Limulus Amoebocyte Lysate assay, commonly used for the quantification of endotoxin, suffers from several limitations. For example, it is sensitive to variations in endotoxin neutralizing factors, detergents, urea, and $\mathrm{pH}^{8,9}$ In addition, cell wall products of fungi and Gram-positive bacteria and polynucleotides can account for false-positive test results. ${ }^{9,10}$ Furthermore, because of its high sensitivity, the Limulus Amoebocyte Lysate assay is prone to exogenous endotoxin contamination. ${ }^{11,12}$ Last, but not least, the interpretation of endotoxin levels in patients with liver disease is particularly challenging, as they may be related to a reduced clearing efficiency of the hepatic reticuloendothelial system and/or an increased presence of liver-derived B-1,3-D-glucans, which can account for false-positive results. ${ }^{13,14}$

In view of these concerns, there is an urgent need for an alternative method to assess endotoxin exposure of the liver in human NASH using peripheral blood. For this purpose, we here assessed the level of Immunoglobulin G $(\operatorname{IgG})$ antibodies in the systemic circulation directed against the inner core of endotoxin, using the Endotoxin Core Antibodies assay (EndoCab). ${ }^{15-17}$ The Endocab IgG levels reflect an integrated antibody response to the endotoxin load over time. This assay has previously been used to study IgG antibodies against endotoxin in other chronic inflammatory diseases, such as inflammatory bowel disease. ${ }^{18}$ Our data show that patients with NASH display elevated plasma EndoCab IgG levels, supporting the association between increased endotoxin plasma levels and NASH.

\section{MATERIALS AND METHODS}

\section{Patients}

Thirty severely obese patients undergoing primary bariatric surgery were sequentially included at the department of General Surgery of the Maastricht University Medical Centre. These Patients had no history of bariatric surgery or other gastrointestinal tract surgery. Patients with acute, recent, or chronic inflammatory diseases 
TABLE 1. Characteristics of the Study Population

\begin{tabular}{lccr}
\hline & Healthy Liver & NASH & $\boldsymbol{P}$ \\
\hline No. patients & 9 & $21^{*}$ & 0.36 \\
Age (y) & $43.7 \pm 2.1$ & $47.3 \pm 2.1$ & 0.63 \\
Sex (M:F) & $3: 6$ & $9: 12$ & 0.33 \\
BMI (kg/m ${ }^{2}$ & $47 \pm 2.3$ & $50.2 \pm 1.9$ & 0.43 \\
DM 2 (yes/no) & $1: 8$ & $5: 16$ & 0.47 \\
HT (yes/no) & $3: 6$ & $12: 9$ & 0.11 \\
Fasting glucose (mmol/L) & $6.0 \pm 0.44(\mathrm{n}=6)$ & $6.7 \pm 2.1(\mathrm{n}=17)$ & 1.00 \\
Total cholesterol (mmol/L) & $4.6 \pm 1.0(\mathrm{n}=5)$ & $5.0 \pm 1.3(\mathrm{n}=14)$ & 0.93 \\
LDL (mmol/L) & $2.8 \pm 1.3(\mathrm{n}=5)$ & $3.2 \pm 1.2(\mathrm{n}=14)$ & 0.96 \\
HDL (mmol/L) & $0.82 \pm 0.11(\mathrm{n}=5)$ & $0.90 \pm 0.18(\mathrm{n}=14)$ & 0.27 \\
FFA (mmol/L) & $0.62 \pm 0.23(\mathrm{n}=5)$ & $36 \pm 17(\mathrm{n}=16)$ & 0.13 \\
AST (IU) & $24 \pm 11(\mathrm{n}=8)$ & $39 \pm 32(\mathrm{n}=16)$ & 0.60 \\
ALT (IU) & $29 \pm 18(\mathrm{n}=8)$ & & \\
\hline
\end{tabular}

Data are presented as mean value $\pm \mathrm{SD}$ ( $\mathrm{n}=$ No. patients). No significant differences with respect to age, sex distribution, BMI, diabetes, hypertension, or plasma parameters were observed between the groups.

*The 21 NASH patients were subdivided according to the Brunt classification in NASH grades and stages; NASH grades (grade 1: $n=11$; grade 2: $n=6$; grade $3: n=4$ ) and NASH stages ( stage $0: n=3$; stage 1: $n=11$; stage 2\&3: $n=7$ ), respectively.

(eg, M. Crohn, Colitis), degenerative diseases, more than $10 \mathrm{~g}$ alcohol consumption per day, other known liver diseases (eg, autoimmune hepatitis or hepatitis B, C) or use of antiinflammatory drugs were excluded from the study. Patient characteristics are summarized in Table 1. This study was approved by the Medical Ethical Board of the Maastricht University Medical Center in line with the ethical guidelines of the 1975 Declaration of Helsinki, and informed consent was obtained in writing from each patient.

\section{Samples}

Venous blood samples and liver biopsies of all patients were obtained and processed as previously described. ${ }^{19}$ Plasma was stored in endotoxin-free vials (Sigma-Aldrich, St. Louis, MO). All 30 liver biopsies were at least $15 \mathrm{~mm}$ in length and had a sufficient number of portal tracts to allow correct evaluation of histologic features. NASH was classified according to the Brunt score $^{20}$ and the NAS score (Kleiner et al) ${ }^{21}$ and NASH severity was assessed according to the criteria of Brunt by an experienced liver pathologist blinded to the clinical context of the biopsies and laboratory parameters. The livers of severely obese patients without NAFLD $(<5 \%$ steatosis $)$ or with a NAS score of 0 to 2 were considered healthy livers. All patients with NASH had a NAS score of more than 5.

\section{Measurements}

Plasma IgG levels against endotoxin were measured using a commercially available sandwich ELISA for human EndoCab (Hycult Biotech, Uden, the Netherlands) according to the manufacturer's protocol. All plasma samples were analyzed in duplicate in the same run. The intra and interassay coefficients of variance were $<10 \%$.

\section{Statistical Analysis}

Data are presented as mean \pm standard deviation. Statistical analysis was done, using Prism 5.0 for Windows (GraphPad Software Inc., San Diego, CA). Differences between groups were analyzed by the Mann Whitney test or the Kruskal Wallis-test followed by Dunn's posttesting. Correlations were calculated using Spearman correlation coefficient. A $P$-value $<0.05$ was considered statistically significant.

\section{RESULTS}

IgG antibodies directed to the core region of endotoxin were detected in all 30 patients with concentrations ranging up to 281 EndoCab standard median-units $\mathrm{IgG}(\mathrm{GMU}) / \mathrm{mL}$. The mean EndoCab $\mathrm{IgG}$ level was $37 \pm 55 \mathrm{GMU} / \mathrm{mL}$ with a median of $28 \mathrm{GMU} / \mathrm{mL}$.

Interestingly, plasma EndoCab IgG was significantly increased by almost 5-fold in patients with NASH compared with patients with healthy livers $(48 \pm 63 \mathrm{GMU} /$ $\mathrm{mL}$ vs. $10 \pm 13 \mathrm{GMU} / \mathrm{mL}, P<0.01$; Fig. 1A). Moreover, plasma IgG levels against endotoxin progressively increased with NASH grade (grade $1 \mathrm{n}=11,29 \pm 37$; grade $2 \mathrm{n}=6$, $58 \pm 51$; grade $3 \mathrm{n}=4,84 \pm 132 \mathrm{GMU} / \mathrm{mL}, P<0.05$, Fig. 1B), suggesting a relation between chronic endotoxin exposure and liver inflammation. NASH stage was not related to plasma EndoCab IgG levels (stage 0, $\mathrm{n}=3$, $57 \pm 27 ; \quad$ stage $1, \quad \mathrm{n}=11, \quad 35 \pm 42 ; \quad$ stage $2 \& 3 \mathrm{n}=7$ $64 \pm 97 \mathrm{GMU} / \mathrm{mL}, P=0.38$, Fig. 1C).

Because immunoglobulin levels, in general, are known to increase with age, we next investigated the relation between EndoCab IgG and age. There was no correlation between EndoCab IgG levels and age $\left(r_{\mathrm{s}}=0.15, P=0.37\right)$, indicating that EndoCab IgG elevation in NASH is a specific phenomenon that cannot be attributed to increasing age. In line with this, the age distribution of the healthy liver and the NASH group was comparable (Table 1). Furthermore, as NASH is associated with diabetes type 2, we also investigated whether plasma Endocab $\mathrm{IgG}$ levels were higher in diabetic patients. Diabetic patients did not show significantly increased plasma Endocab IgG levels compared with patients without diabetes $(40 \pm 13 \mathrm{GMU} /$ $\mathrm{mL}$ vs. $36 \pm 12 \mathrm{GMU} / \mathrm{mL}, P=0.45)$.

\section{DISCUSSION}

Gut-derived endotoxin is suggested to be an important player in the pathogenesis of NASH. ${ }^{2,4}$ Hence, there is an increasing interest in the assessment of endotoxin exposure of the liver in humans. However, the analysis of endotoxin is complicated due to technical and sampling issues. Here, we have studied the potential of the EndoCab assay as an indicator of chronic hepatic endotoxin exposure in human NASH. Our data reveal an association between biopsyproven human NASH and elevated plasma levels of IgG 

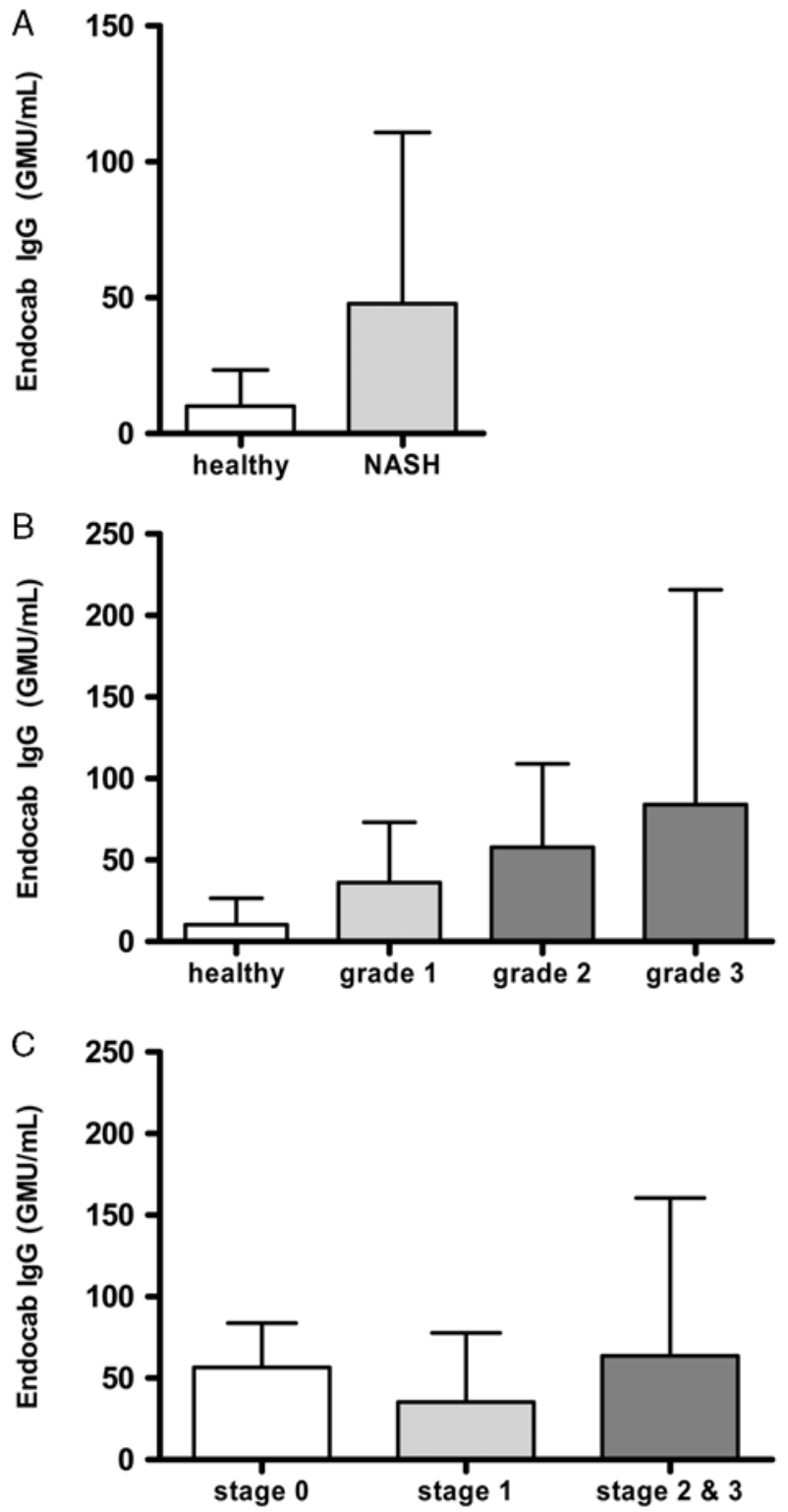

FIGURE 1. A, Elevated plasma EndoCab lgG levels are associated with NASH. Plasma IgG levels against endotoxin are almost 5 -fold increased in severely obese patients with NASH $(n=21)$ compared with severely obese controls with healthy livers $(n=9, N A S H$ $48 \pm 63 \mathrm{GMU} / \mathrm{mL}$ vs. healthy $10 \pm 13 \mathrm{GMU} / \mathrm{mL} ; P<0.01)$. B, Plasma $\operatorname{lgG}$ levels against endotoxin increase with NASH severity as defined by the Brunt criteria (healthy $n=9,10 \pm 13.4$; grade $1 n=11$, $29 \pm 37$; grade $2 \mathrm{n}=6,58 \pm 51$; grade $3 \mathrm{n}=4,84 \pm 132 \mathrm{GMU} / \mathrm{mL}$, $P<0.05)$. C, Plasma lgG levels against endotoxin are unrelated to $\mathrm{NASH}$ stage as scored by the Brunt criteria (stage $0, \mathrm{n}=3,57 \pm 27$; stage $1, \mathrm{n}=11,35 \pm 42$; stage $2 \& 3 \mathrm{n}=764 \pm 97 \mathrm{GMU} / \mathrm{mL}, P=0.38$ ).

antibodies against the core region of endotoxin, supporting a possible role for chronic hepatic endotoxin exposure in the development of NASH.

The analysis of immunoglobulins against endotoxin has several advantages over the direct detection of endotoxin. First of all, it is not affected by contamination, and it detects a physically more stable molecule. Further- more, because of the relatively long half-life (21 days) of IgG antibodies, measurement of IgG against endotoxin provides an indication of endotoxin exposure over time. Importantly, systemic plasma Endocab IgG levels were previously found to be correlated to plasma endotoxin levels. ${ }^{17}$ In addition, plasma levels of $\mathrm{IgG}$ against endotoxin may also reflect the responsiveness of the immune system toward this potent immunostimulatory compound, which, in the pathogenesis of $\mathrm{NASH}$, could be more relevant than measuring endotoxin directly. Indeed, we found that plasma IgG levels against endotoxin progressively increased with NASH severity, suggesting a relation between chronic endotoxin exposure and liver inflammation. However, taking into consideration that the study population size is limited, these findings will need to be validated in a larger cohort.

Antiendotoxin IgG levels have previously been used to study the antibody response to endotoxin in other chronic inflammatory diseases associated with chronic endotoxin load, such as inflammatory bowel disease and colitis. In line with our results, these patients displayed significantly elevated plasma IgG levels. ${ }^{18}$ To our knowledge, a potential association between plasma Endocab IgG levels and obesity-associated chronic inflammatory disorders, such as diabetes or atherosclerosis has not been earlier reported. However, in our study population, no relation between Endocab IgG and diabetes type 2, hypertension, or gender was observed.

Of note, IgG antibodies against endotoxin might also have a functional role with respect to activation of innate immunity in NASH. In particular, immune complexes between IgG antibodies and endotoxins may cause deposition of complement component Clq. This Clq deposition in turn may further aggravate liver inflammation by initiating complement activation and promoting neutrophil infiltration, as we previously showed in human NASH. ${ }^{19}$ Future studies will therefore focus on the identification of EndoCab IgG in the liver in relation to complement activation.

Taken together, our findings support the hypothesis that hepatic endotoxin exposure contributes to the development of NASH. The detection of plasma IgG levels against endotoxin may represent a novel method to assess chronic hepatic endotoxin exposure in patients with NASH.

\section{ACKNOWLEDGMENTS}

The authors thank Jeroen Nijhuis and Yanti Slaats for collecting tissue samples in the initial phase of the study.

\section{REFERENCES}

1. Duvnjak M, Lerotic I, Barsic N, et al. Pathogenesis and management issues for non-alcoholic fatty liver disease. World $J$ Gastroenterol. 2007;13:4539-4550.

2. Miele L, Valenza V, La Torre G, et al. Increased intestinal permeability and tight junction alterations in nonalcoholic fatty liver disease. Hepatology. 2009;49:1877-1887.

3. Sabate JM, Jouet P, Harnois F, et al. High prevalence of small intestinal bacterial overgrowth in patients with morbid obesity: a contributor to severe hepatic steatosis. Obes Surg. 2008;18: 371-377.

4. Wigg AJ, Roberts-Thomson IC, Dymock RB, et al. The role of small intestinal bacterial overgrowth, intestinal permeability, endotoxaemia, and tumour necrosis factor alpha in the pathogenesis of non-alcoholic steatohepatitis. Gut. 2001;48: 206-211.

5. Farhadi A, Gundlapalli S, Shaikh M, et al. Susceptibility to gut leakiness: a possible mechanism for endotoxaemia in nonalcoholic steatohepatitis. Liver Int. 2008;28:1026-1033. 
6. Thuy S, Ladurner R, Volynets V, et al. Nonalcoholic fatty liver disease in humans is associated with increased plasma endotoxin and plasminogen activator inhibitor 1 concentrations and with fructose intake. J Nutr. 2008;138:1452-1455.

7. Lumsden AB, Henderson JM, Kutner MH. Endotoxin levels measured by a chromogenic assay in portal, hepatic and peripheral venous blood in patients with cirrhosis. Hepatology. 1988;8:232-236.

8. Cohen J, McConnell JS. Observations on the measurement and evaluation of endotoxemia by a quantitative limulus lysate microassay. J Infect Dis. 1984;150:916-924.

9. Ditter B, Becker KP, Urbaschek R, et al. Quantitative endotoxin determination. Automated kinetic Limulus amebocyte lysate microtiter test with measurement of sample-related interferences. Arzneimittelforschung. 1983;33:681-687.

10. Cohen O, Reichenberg A, Perry C, et al. Endotoxin-induced changes in human working and declarative memory associate with cleavage of plasma "readthrough" acetylcholinesterase. J Mol Neurosci. 2003;21:199-212.

11. Hurley JC. Endotoxemia: methods of detection and clinical correlates. Clin Microbiol Rev. 1995;8:268-292.

12. Cohen J. The detection and interpretation of endotoxaemia. Intensive Care Med. 2000;26(suppl 1):S51-S56.

13. Shiomi S, Kuroki T, Ueda T, et al. Use of immobilized histidine in assay for endotoxin in patients with liver disease. $J$ Gastroenterol. 1994;29:751-755.
14. Nakao A, Yasui M, Kawagoe $T$, et al. False-positive endotoxemia derives from gauze glucan after hepatectomy for hepatocellular carcinoma with cirrhosis. Hepatogastroenterology. 1997;44:1413-1418.

15. Barclay GR, Scott BB, Wright IH, et al. Changes in antiendotoxin-IgG antibody and endotoxaemia in three cases of gram-negative septic shock. Circ Shock. 1989;29:93-106.

16. Scott BB, Barclay GR. Endotoxin-polymyxin complexes in an improved enzyme-linked immunosorbent assay for $\mathrm{IgG}$ antibodies in blood donor sera to gram-negative endotoxin core glycolipids. Vox Sang. 1987;52:272-280.

17. Clements WD, Erwin P, McCaigue MD, et al. Conclusive evidence of endotoxaemia in biliary obstruction. Gut. 1998;42: 293-299.

18. Gardiner KR, Halliday MI, Barclay GR, et al. Significance of systemic endotoxaemia in inflammatory bowel disease. Gut. 1995;36:897-901.

19. Rensen SS, Slaats Y, Driessen A, et al. Activation of the complement system in human nonalcoholic fatty liver disease. Hepatology. 2009;50:1809-1817.

20. Brunt EM, Janney CG, Di Bisceglie AM, et al. Nonalcoholic steatohepatitis: a proposal for grading and staging the histological lesions. Am J Gastroenterol. 1999;94:2467-2474.

21. Kleiner DE, Brunt EM, Van Natta M, et al. Design and validation of a histological scoring system for nonalcoholic fatty liver disease. Hepatology. 2005;41:1313-1321. 